\title{
ANAESTHETIC MANAGEMENT OF A PATIENT WITH A GIANT OVARIAN TUMOUR: A CASE REPORT
}

\author{
Prabhatirani Mishra ${ }^{1}$, Parsuram Jena², Dhaneswari Jena ${ }^{3}$
}

${ }^{1}$ Assistant Professor, Department of Anesthesia, MKCG Medical College.

${ }^{2}$ Assistant Professor, Department of Medicine, SCB Medical College.

${ }^{3}$ Associate Professor, Department of Community Medicine, MKCG Medical College.

\begin{abstract}
Due to advanced medical sciences and improved modern technology, giant tumours are rarely found now-a-days. In addition to basic pathology, these are mainly characterised by its huge size, causing pressure symptoms. Here, we are reporting a case of giant ovarian tumour of $35 \mathrm{~kg}$ weight successfully removed and managed by careful and meticulous peri-operative management.
\end{abstract}

\section{KEYWORDS}

Giant Ovarian Tumour, General Anaesthesia, Supine Hypotension Syndrome, Re-Expansion Pulmonary Edema.

HOW TO CITE THIS ARTICLE: Prabhatirani Mishra, Parsuram Jena, Dhaneswari Jena. "Anaesthetic Management of A Patient with a Giant Ovarian Tumour: A Case Report." Journal of Evolution of Medical and Dental Sciences 2015; Vol. 4, Issue 102, December 21; Page: 16806-16807, DOI: 10.14260/jemds/2015/2521

\section{CASE REPORT}

A 35 years old female of very thin built presented with a huge abdominal swelling. The swelling has gradually increased to present size over a period of five years. Weight of the patient was $70 \mathrm{~kg}$, abdominal girth was $140 \mathrm{~cm}$ with stretched umbilicus and prominent abdominal superficial veins. Patient was dyspnoeic on supine position. Apart from routine investigations, ECG, ECHO, ABG, Liver Function Test was done and results were within normal limits. Pulmonary Function Test shows restrictive type of lung disease with FVC 77.3\%, FEV $175.4 \%$. X-ray chest showed upward displacement of diaphragm. CT abdomen showing both solid and cystic masses arising from right ovary occupied both pelvic and abdominal spaces. Patient was posted for exploratory laparotomy and taken up for surgery with 2 Units of whole blood and 3 units FFP in hand.

In the OT table, patient on semi-recumbent position, premedicated with injection Pentaprazole, Inj. Ondansetron and Inj. Glycopyrolate 60 minute prior to surgery. Monitors like ECG, $\mathrm{O}_{2}$ saturation $\left(\mathrm{SPO}_{2}\right)$ Non-Invasive $\mathrm{BP}$ (NIBP) and temperature monitors were connected. A16G I.V. line secured in a forearm vein. In-room air $\mathrm{O}_{2}$ saturation was $92 \%$. Patient in semi-recumbent position adequately pre-oxygenated and pre- medicated with Inj. Midazolam and Inj. Fentanyl. She was induced with Inj. Thiopentone. Rapid sequence intubation was done with Inj. Succinylcholine with cricoid pressure. Endotrachial intubation was done with cuffed ET tube and maintained by IPPV with $\mathrm{O}_{2} ; \mathrm{N}_{2} \mathrm{O}$ and $0.5-1 \%$ isofluranel. Oxygen saturation fall to $85-87 \%$ after premedication even ventilation with $100 \% \mathrm{O}_{2}$.

After abdominal incision, $\mathrm{O}_{2}$ saturation was improved to 95\%. Right IJV and right radial artery canulated for invasive monitoring. Continuous ECG, SPO2, HR, IBP, CVP, UO, temp and ABG monitoring was done. Huge mass with both solid and cystic components arising from right ovary was removed. Intraoperative BP was maintained between $150-160 \mathrm{mmHg}$ (Systolic) and $90-100 \mathrm{mmHg}$ (Diastolic). After removal of tumour, there was severe bleeding and sudden fall of BP.

Financial or Other, Competing Interest: None.

Submission 29-11-2015, Peer Review 30-11-2015,

Acceptance 15-12-2015, Published 21-12-2015.

Corresponding Author:

Dr. Prabhatirani Mishra,

Department of Anaesthesiology,

MKCG Medical College,

Berhampur.

E-mail: prabhati_rani@yahoo.co.in

DOI:10.14260/jemds/2015/2521
Which was managed with crystalloid, blood and FFP. At the end of the surgery, patient was reversed with Inj. Glycopyrolate and Inj. Neostigmine and extubated. For further monitoring, patient was shifted to ICU and analgesia maintained with Inj. Tramadol 50mg IM 8 hourly and Inj. Diclofenac Sodium $75 \mathrm{mg}$ IM 8 hourly. Patient was haemodynamically stable. On third post-operative day, patient's weight was $35 \mathrm{~kg}$. Post-operative $\mathrm{x}$-ray of chest revealed adequate expansion of lungs.

\section{DISCUSSION}

We present the anaesthetic management of a patient with a giant ovarian tumour without major complications. There has been considerable debate over the merits of preoperative drainage of the cyst. The potential hazards of drainages are the possibility of intra-peritoneal spillage and seeding of ovarian carcinoma and increased risk of intraabdominal infection, haemorrhage and adhesions.(1) Our case being a solid tumour, preoperative drainage was not attempted.

General Anaesthesia administration in giant abdominal tumours have several associated risk.(2,3) Circulatory and respiratory management are usually difficult. Due to these risks, it has been recommended that the tumour mass is to be reduced preoperatively to prevent circulatory and respiratory depression which is possible only cystic type of masses.(2,3)

The difficult parts in anaesthetic management are 1) The influence on circulation and respiration due to pressure on the abdominal great vessels and lungs. Therefore, we put the patients on semi recumbent position. It prevents hypoxemia due to compression of lungs as well as supine hypotension syndrome. 2) A risk of aspiration during intubation was prevented by cricoid pressure. 3) Risk of massive bleeding was managed with crystalloids, blood and FFP. 4) Rapid expansion pulmonary oedema may develop due to rapid expansion of chronically collapsed lung through a mechanism of increased pulmonary vascular permeability. $(4,5)$ To prevent RPE, we choose to re-expand the collapsed lungs very slowly and maintain a relatively low TV.

The post-operative course was relatively uncomplicated in our patient. In this case coagulation abnormalities were not seen. Six of eight reported cases encounter post-operative ventilator difficulty. $(6,7,8$,$) Post-operative pain is one cause of it$ which was managed with inj. Tramadol and inj. Diclofenac sodium.

Intraoperative and postoperative hypothermia, which is a major complication, which was avoided by giving worm saline infusion to prevent intraoperative heat loss. 
Gaseous distention due to intestinal ileus has been reported in many cases.(9) However, in our case, paralytic ileus did not develop and oral feeding started on $3^{\text {rd }}$ postoperative day. The patient was discharged on $12^{\text {th }}$ postoperative day.

This patient was at risk of deep vein thrombosis and pulmonary embolism, which was managed by giving low molecular weight heparin and early mobilization.

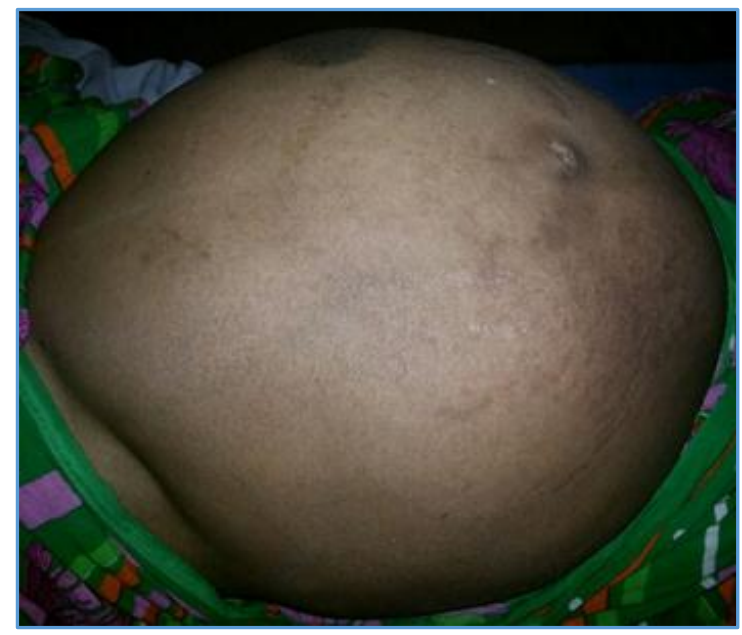

Fig. 1: Large Abdominal Mass

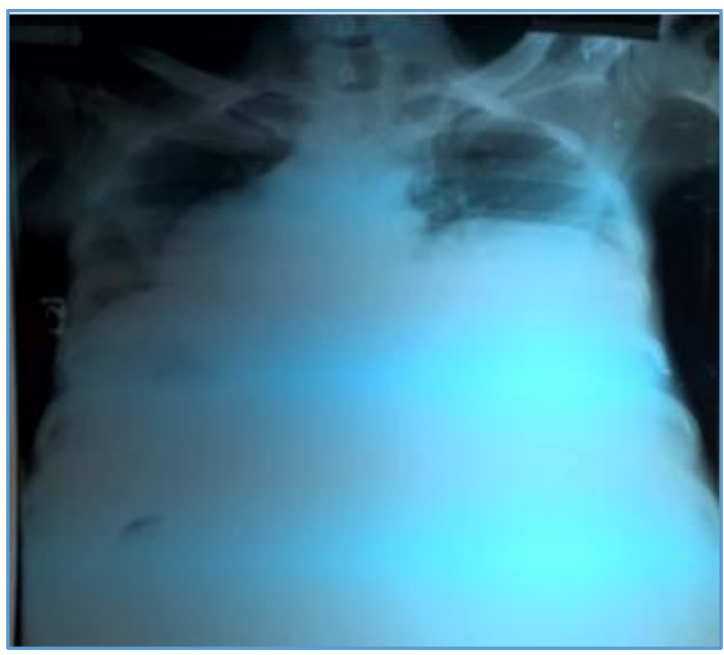

Fig. 2: Preoperative X-Ray Chest

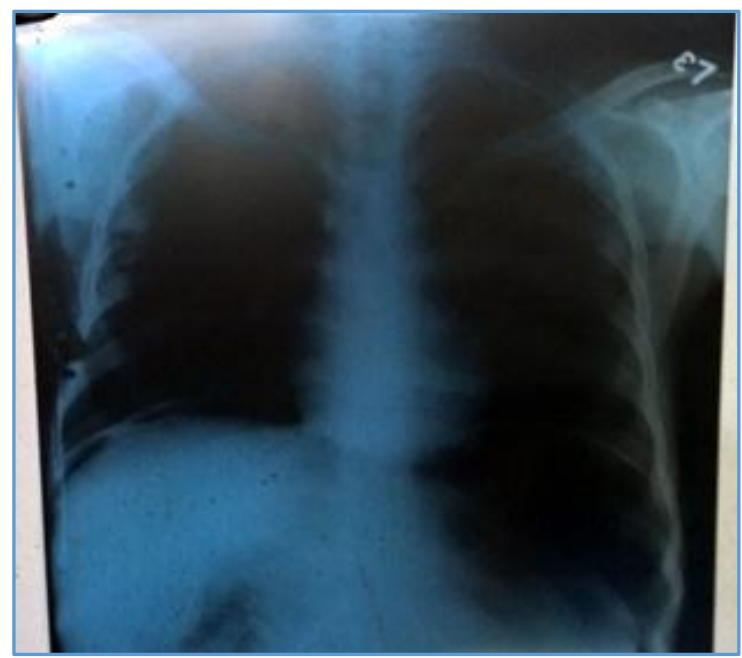

Fig. 3: Post-Operative X-Ray Chest

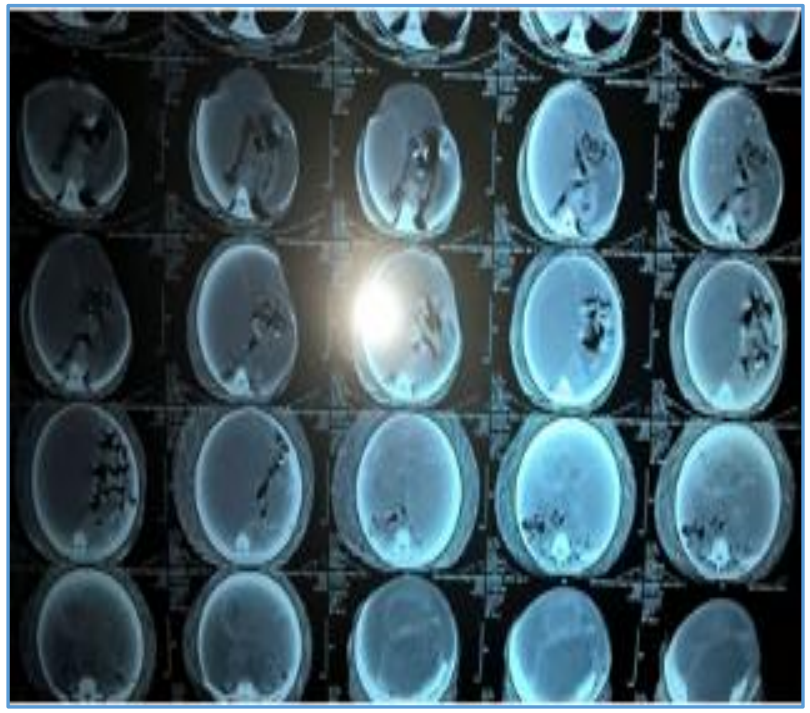

Fig. 4: CT Scan Abdomen

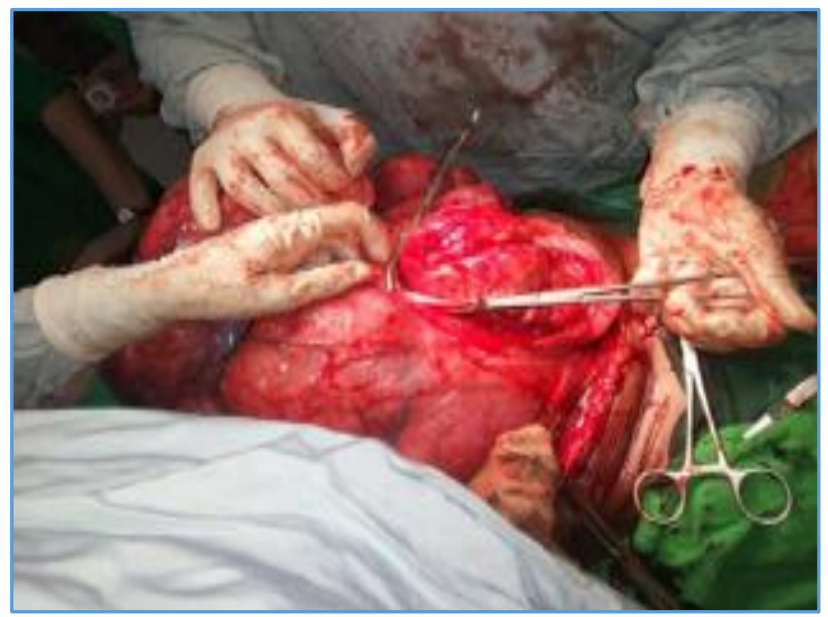

Fig. 5: Removal of Tumor Mass

\section{REFERENCES}

1. Bezjian AA, O'leary JA: A massive Ovarian tumour - A Case report. Obstet Gynecol 1971;38:214-216.

2. Nishiyama T, Hanaoka K: Same day drainage and removal of a giant ovarian cyst. Can J Anaesth 1977;44:1087-1090.

3. Kotera A, Kouzuma S, Miyazaki N, et al.: Anesthetic management of a patient with an ultra huge ovarian tumor. Masui 2009;58:907-909.

4. Takahiro M, Kiyoyasu K: Re-expansion Pulmonary Edema (RPE) during surgery for intraabdominal giant tumor. Masui 2008;57:191-196.

5. Mahfood S, Hix WR, Aaron BL, et al.: Re-expansion pulmonary edema. Ann Thorac Surg 1988;45:340-345.

6. Drife J0, Trotter GA. Britain's biggest ovarian cyst. Br Med J 1981;283:1661-1662.

7. Hunter DJS. Management of a massive ovarian cyst. Obstet Gynecol 1980;56:254-255.

8. Morrison P, Morgan G. Removal of a giant ovarian cyst. Anaesthetic and intensive care management. Anaesthesia 1987;42:965-973.

9. Ovarian cystectomy - anaesthetic management: Pandya, Symmonds RE, Spraitz AF, et al. Large ovarian tumour, Report of a case. Obstet Gynecol 1963;22:473-477. 